\title{
Primary mucosa-associated lymphoid tissue lymphoma of the entire esophagus diagnosed by endoscopic ultrasound-guided fine needle aspiration
}
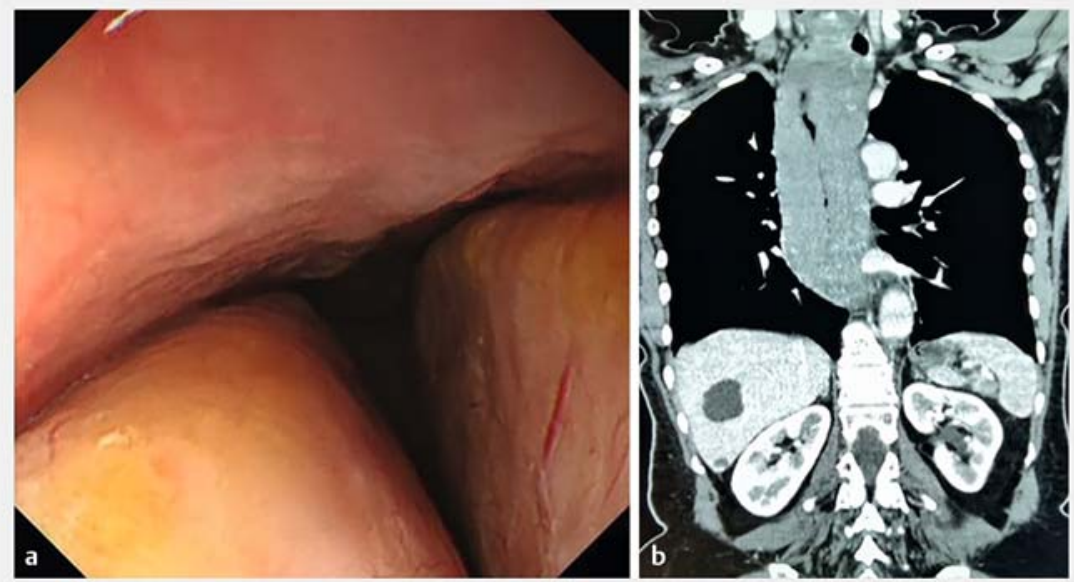

- Fig. 1 a Upper gastrointestinal endoscopy showed a large mass protruding into the lumen with an intact mucosa, lobulated, extending from $16 \mathrm{~cm}$ from the incisor teeth to $38 \mathrm{~cm}$ just above the gastroesophageal junction. b A computed tomography scan demonstrated a significant thickening of the entire esophageal wall. No mediastinal lymphadenopathy was observed.
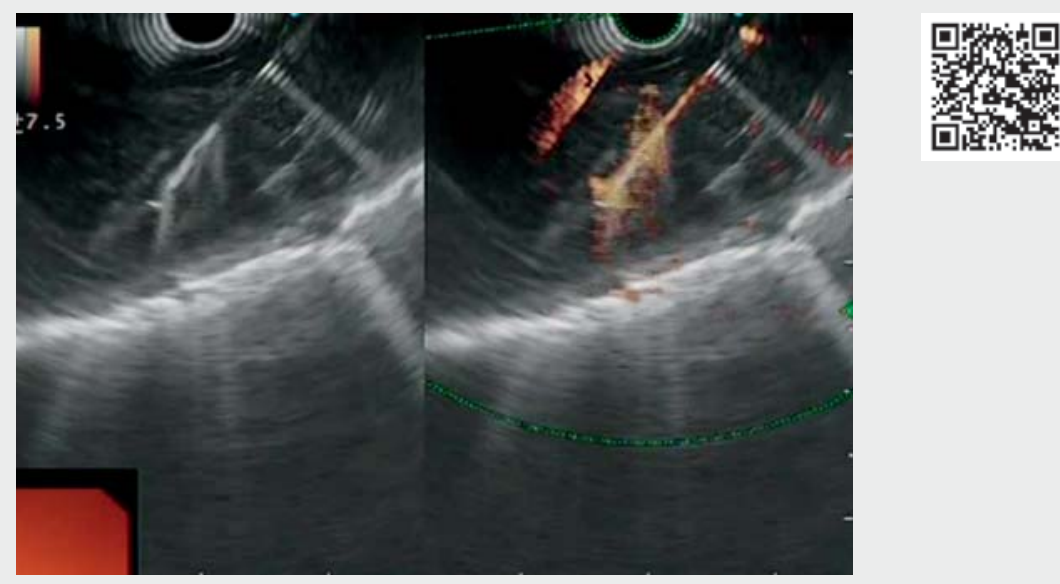

$\checkmark$ Video 1 A mass protruded into the lumen with an intact, lobulated, and yellowish mucosa. Endoscopic ultrasound-guided fine needle aspiration with a 19-G needle was performed. During the procedure, $0 \mathrm{ml}$ of negative pressure and two needles were used.

A 62-year-old woman was admitted for progressive dysphagia and weight loss over a 6-month period. She had no evidence of any abnormal laboratory findings or immunosuppressive diseases.
Physical examinations were also unremarkable.

Gastroscopy showed, despite sufficient insufflation, a large soft, elastic mass protruding into the entire esophagus

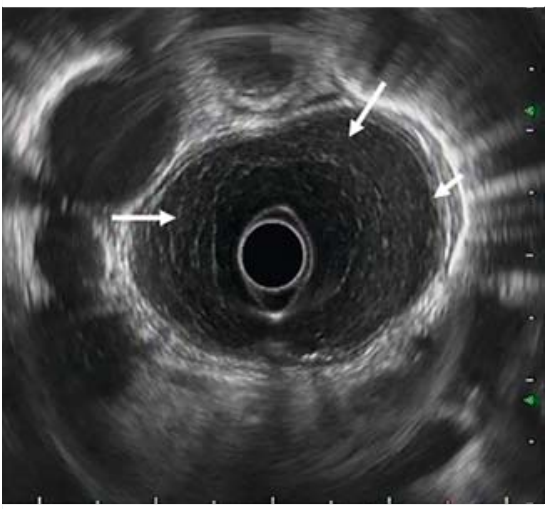

- Fig. 2 Endoscopic ultrasound demonstrated a heterogeneous mass in the submucosa with partial involvement of the muscularis propria (small white arrow). A hyperechoic area (large white arrows) is also seen.

lumen with normal mucosa, extending from $16 \mathrm{~cm}$ from the incisor teeth to $38 \mathrm{~cm}$ just above the gastroesophageal junction (-Fig.1a). Enhanced mediastinal computed tomography (CT) revealed a thickening of the entire esophageal wall, with a maximum diameter of $27 \mathrm{~mm}$, producing severe luminal narrowing. No mediastinal lymph node enlargement was observed (\Fig.1 b). Endoscopic ultrasound (EUS) demonstrated a lesion affected from the introitus esophagus to the distal end, with an obviously thickened wall layer. This thickening was mainly accentuated in the submucosa compatible with the microcalcifications that were seen ( $\mathbf{F i g . 2}$ ). Partial involvement of the muscularis propria was noted. The internal echotexture was somewhat heterogeneous, with both isoechoic and hyperechoic areas. Elastography indicated the mass was soft. Endoscopic ultrasound-guided fine needle aspiration (EUS-FNA) was performed through a 19-gauge needle (Cook Endoscopy, Winston-Salem, NC, USA) (\Video 1). Primary mucosa-associated lymphoid tissue (MALT) lymphoma was confirmed by histopathological ex- 


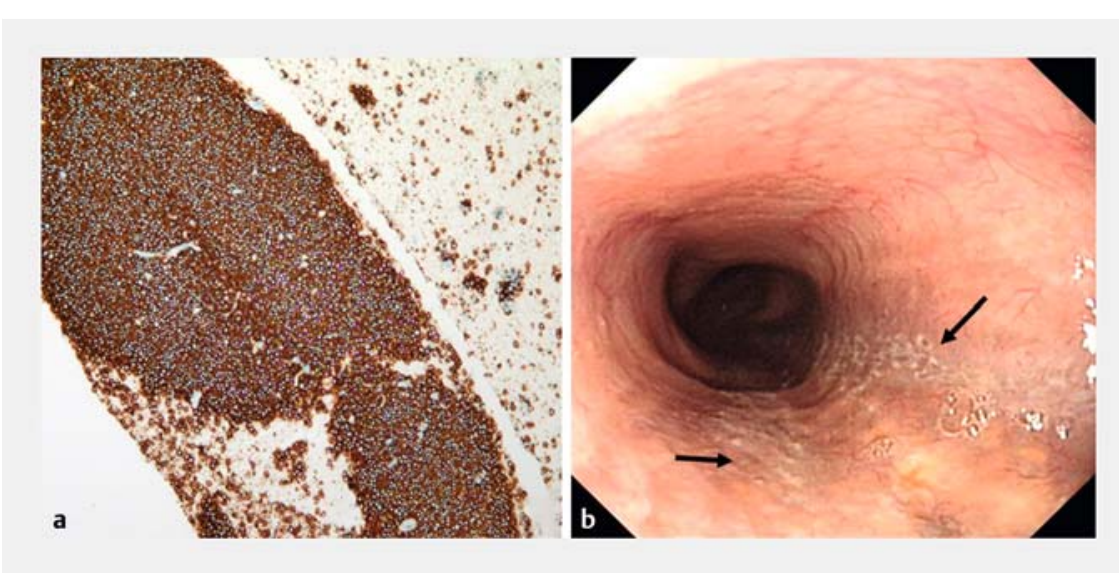

- Fig. 3 a Histopathological examination showed a significant submucosal infiltration of lymphocytes with B-cell markers, etc. $(C D 20+)(100 \times)$. b After 4 months of chemotherapy, reexamination gastroscopy showed the esophageal mucosa with a white scar (black arrows) and significant improvement.

amination ( $>$ Fig. $\mathbf{3 a}$ a). The patient was then treated with four courses of chemotherapy with rituximab, cyclophosphamide, vincristine, doxorubicin, and prednisolone. Her esophagus showed significant remission with a decrease of thickening, and dysphagia had disappeared ( $\triangleright$ Fig. $\mathbf{3} \mathbf{b}$ ).

Primary gastrointestinal (GI) lymphoma, especially of the esophagus, is an extremely rare site of involvement, with fewer than 30 cases in the literature [1]. Endoscopic findings are unspecific with varying presentations, including polypoid mass with or without ulceration, varicoid stenosis, strictures, or submucosal nodules, among others [2-4]. However, almost no cases involved the entire esophagus. Given such a diverse spectrum of presentations, histology is mandatory to confirm diagnosis. Unfortunately, many of these cases were diagnosed surgically [5]. FNA biopsy is a safe method and indeed provides a high diagnostic yield in Gl lymphomas.

Endoscopy_UCTN_Code_TTT_1AO_2AB

Funding

National Natural Science Foundation

of China

http://dx.doi.org/10.13039/

501100001809

No. 81800467,81770637

\section{Competing interests}

The authors declare that they have no conflict of interest.

\section{The authors}

Chaoqun Han ${ }^{1}$ " , Rong Lin ${ }^{1}$, Mingyao $\mathrm{Xu}^{2}$, Jun Liu', Zhen Ding ${ }^{1}$

1 Division of Gastroenterology, Union Hospital, Tongji Medical College, Huazhong University of Science and Technology, Wuhan, China

2 Department of Endoscopy, Hubei Cancer Hospital, Wuhan, China

\section{Corresponding author}

\section{Zhen Ding, MD}

Division of Gastroenterology, Union Hospital, Tongji Medical College, Huazhong University of Science and Technology, 1277 Jiefang Avenue, Wuhan, Hubei Province, 430022, China

Fax: +86-27-85726057

docd720@126.com

[1] Ma Q, Zhang C, Fang Sg et al. Primary esophageal mucosa-associated lymphoid tissue lymphoma: a case report and review of literature. Medicine 2017; 96: e6478

[2] Ogura T, Tajika M, Hijioka S et al. First report of a mucosa-associated lymphoid tissue (MALT) lymphoma of the esophagus diagnosed by endoscopic ultrasound-guided fine-needle aspiration (EUS-FNA). Endoscopy 2012; 44: 167-168

[3] Musquer N, Zidane-Marinnes M, Dib M. Primary mucosa-associated lymphoid tissue lymphoma of the entire esophagus. Gastrointest Endosc 2017; 86: 560-561

[4] Shim CS, Lee JS, Kim JO et al. A case of primary esophageal B-cell lymphoma of MALT type, presenting as a submucosal tumor. J Korean Med Sci 2003; 18: 120-124

[5] Soon M-S, Yen H-H, Soon A et al. Primary esophageal B-cell lymphoma: evaluation by EUS. Gastrointest Endosc 2005; 61: 901903

\section{Bibliography}

Endoscopy 2022; 54: E694-E695

DOI 10.1055/a-1722-2386

ISSN 0013-726X

published online 28.2.2022

(c) 2022. Thieme. All rights reserved.

Georg Thieme Verlag KG, Rüdigerstraße 14, 70469 Stuttgart, Germany

\section{ENDOSCOPY E-VIDEOS}

https://eref.thieme.de/e-videos

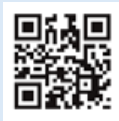

Endoscopy E-Videos is an open access online section, reporting on interesting cases and new techniques in gastroenterological endoscopy. All papers include a high quality video and all contributions are freely accessible online. Processing charges apply (currently EUR 375), discounts and wavers acc. to HINARI are available.

This section has its own submission website at https://mc.manuscriptcentral.com/e-videos

\footnotetext{
* These authors contributed equally to this work.
} 